\title{
Cellulose/Exosome Nanocarrier for Improved Prolonged Release of 5-Fluorouracil: Preparation, Characterization, Drug Release Behavior and Cytotoxicity
}

Maryam Saeidifar ( $\sim$ m.saidifar@gmail.com )

Materials and Energy Research Center https://orcid.org/0000-0002-1116-2932

Mobina Seyedahmadi

Materials and Energy Research Center

Jafar Javadpour

Iran University of Science and Technology

Hamid Reza Rezaei

Iran University of Science and Technology

Research Article

Keywords: Drug Release, Cellulose, Exosome, anticancer, Release mechanism

Posted Date: December 13th, 2021

DOI: https://doi.org/10.21203/rs.3.rs-1102085/v1

License: (c) (i) This work is licensed under a Creative Commons Attribution 4.0 International License.

Read Full License 


\section{Abstract}

Designing of nanoparticle drug delivery systems and improving the efficacy of anticancer drugs are a great deal of effort in the recent years. In this study, a novel biocompatible nanocarrier based on bacterial cellulose (BC) in presence of exosome (Exo) was prepared to controlled release of 5-fluorouracil (5-FU), (5FU.Exo@BC). The physicochemical properties of 5-FU.Exo@BC was characterized using field emission scanning electron microscopy (FESEM), Differential Scanning Calorimetry (DSC), Fourier-transform infrared spectroscopy (FTIR), and X-ray Diffraction (XRD) techniques that confirmed the successful preparation of 5-FU.Exo@BC. The release behavior of 5-FU.Exo@BC compared to 5-FU and 5-FU@BC demonstrated a significant sustained release during $162 \mathrm{~h}$. The release mechanism of the above three systems followed Korsmeyer-peppas with non-Fickian diffusion for 5-FU@BC and 5-FU.Exo@BC. In addition, the viability of HT-29 cells (human colon cancer cell line), towards BC, 5-FU@BC and 5FU.Exo@BC indicated the promising efficacy of 5-FU into 5-FU.Exo@BC. Subsequently, the prepared bionanocomposite could be proposed as a potential drug delivery system with effective controlled-release function.

\section{Introduction}

Cancer treatment is one of the prospective uses of nanotechnology [1]. Natural polymers have over the past decades been thoroughly examined for use in drug delivery, in regard to their biocompatibility and biodegradability, and their potential to deliver drugs and genes to targeted organs [2, 3]. Exosomes as a promising nanocarriers for drug delivery could be made of various kinds of biomolecule such as proteins, carbohydrates, lipids, and nucleic acids [4]. Exosomes can present improved blood stability, enabling them to move long distances under both physiological and pathological conditions inside the body. Moreover, having a hydrophilic core renders exosomes favorable to host water-soluble drugs [5].

An anti-metabolite, 5-Fluorouracil (5-FU) exhibits broad-spectrum anti-cancer activity against solid tumors [6]. 5-FU, a pyrimidine analog, is an exclusively 'S-phase' active chemotherapeutic agent and acting as a thymidylate synthase inhibitor and thus impeding DNA synthesis [7]. Over the last forty years, 5-FU has been exploited against cancers like colon cancer, playing practically the role as a thymidylate synthase inhibitor. However, drug resistance remains a major obstacle in the clinical application of 5-FU [8]. Apart from its limited clinical uses, it is vital to develop effective carriers to enhance 5-FU delivery, leading to better anticancer efficacy [9].

There has been great effort on developing an efficient cellulose carrier system to control the drug concentration and release rate. Bacterial cellulose (BC) has drawn considerable attention in medical, pharmaceutical, and other related areas due to biocompatibility and non-toxicity besides physicochemical properties such as its intrinsic physical, mechanical, and biological qualities [10]. Cellulose can be produced by various acetic acids producing bacterial strains of the genera Acetobacter, Gluconobacter, Gluconacetobacter and Komagateibacter. [11]. Recently, BC has attracted special consideration in biomedical applications because the polymer is nontoxic, biocompatible, moldable, and 
transparent [12]. Moreover, its high-porosity geometry and hydrophilic structure facilitate the absorption and carrying of high quantities of liquid drug for the polymer. This is vital in wound dressing and tissue engineering [13]. BC has been thoroughly examined for medical applications; still, rather little effort has been detailed in cancer treatment. Regarding its physicochemical features and efficiency in developing composite materials, the research focus is turning to extending the role of $B C$ in cancer treatment $[14,15]$. In the other hand, exosomes (Exo), the endogenous nanocarriers that can deliver biological information between cells, were recently introduced as a new kind of drug delivery system [16].

Regarding the potential of $\mathrm{BC}$ and Exo to sustained drug release, in the present study, the combination of bacterial cellulose (BC) and exosome (Exo) was prepared as a nanocarrier for prolonged release of 5Flurouracil (5-FU). The characterization was performed using field emission scanning electron microscopy (FESEM), Differential Scanning Calorimetry (DSC), Fourier-transform infrared spectroscopy (FTIR), and X-ray Diffraction (XRD) techniques. After that, the drug release and the release mechanism were examined and the results were compared to 5-FU and 5-FU@BC. To confirm of improvement effectiveness, the cytotoxicity of nanocarriers containing 5-FU against colon cancer cell line, HT-29 was evaluated.

\section{Materials And Methods}

Phosphate buffer saline tablet (PBS), and dimethyl sulfoxide (DMSO), RPMI1640, 3-(4, 5-dimethylthiazol2-yl)-2, 5-diphenyltetrazolium bromide (MTT) were purchased from Sigma-Aldrich (Germany). Exosome $(24.3 \mu \mathrm{M})$ derived from human Amniotic Fluid, were isolated by differential sedimentation (Ultracentrifugation) method according to previous report [17]. 5-Fluorouracil (5-FU, $50 \mathrm{mg} / \mathrm{ml}$ ) were received from Ebewe Co., Austria. Bacterial cellulose was purchased from Nano Zist Polymer Pars Co. Tehran, Iran that was prepared according to the previous report $[18,19]$, with $1 \mathrm{~mm}$ thickness. The human colon cancer cell line, HT-29, was obtained from the Cell Bank of the Histogenotech institute in Tehran (Iran). Deionized water ( $\mathrm{DI})$ was used in all of the experiments. The other reagents and solvents were analytical grad and purchased from Merck company (Germany).

The Fourier transform infrared (FT-IR) spectra were recorded using a Perkin Elmer company (spectrum400-model) FT-IR spectrometer in a $\mathrm{KBr}$ disk in the range of $4000-400 \mathrm{~cm}^{-1}$. Differential Scanning Calorimetry (DSC), DSC-1 (TA Instruments, Mettler Toledo, Switzerland) Model was used to investigation of the crystallinity, purity, degradation of a variety of samples. The samples were weighed in a standard open aluminum pan, while an empty pan of the same type was used as a reference. The heat running for each sample was set from $23^{\circ} \mathrm{C}$ to $400^{\circ} \mathrm{C}$ at a $10^{\circ} \mathrm{C} / \mathrm{min}$ increment rate, using nitrogen as a purge gas with the rate of nitrogen atmosphere being $40 \mathrm{ml} / \mathrm{min}$. Calibration of temperature and heat flow was performed with indium and zinc. Absorption spectroscopy was adopted to study the drug release behavior using a T80 + UV-Vis Spectrophotometer, PG Instruments Ltd. Topographical and elemental information at specific magnifications with a virtually unlimited depth of samples was studied using field emission scanning electron microscopy (FESEM) where each sample was spin-coated on a microscope slide, which remained for 1 day at room temperature to dry. Then, the slides were sputter- 
coated with a layer of gold, and images were taken by TESCAN MIRA3, (voltage of $15.0 \mathrm{Kv}$, current intensity of $30 \mathrm{~A}$ ). The XRD pattern of samples was recorded using a Powder X-ray diffractometer (PW $3710 \mathrm{mpd}$ control) with the copper line as the source of radiation at the voltage of $40.0(\mathrm{kV})$ and current

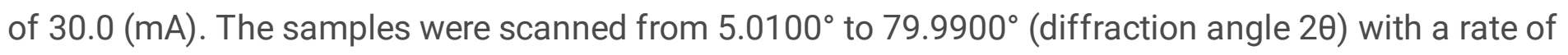
one second per step, using a zero-background sample holder.

\subsection{Preparation of samples}

$\mathrm{BC}$ sheets (approximately $1.1 \mathrm{~cm}^{2}$ area, $2.2 \pm 0.2 \mathrm{mg}$ weight) were put in $10 \mathrm{ml} \mathrm{DI}$ water at the incubator shaker under the constant condition of $30^{\circ} \mathrm{C}$ for $48 \mathrm{~h}$.

\subsubsection{5-FU@BC}

$22 \mu \mathrm{l} 5-\mathrm{FU}(50 \mathrm{mg} / \mathrm{ml})$ was added to $978 \mathrm{ml} \mathrm{DI}$ water and then, a BC sheet was placed in the solution (the ratio of $5-\mathrm{FU}$ to $\mathrm{BC}$ was $2: 4 \mathrm{w} / \mathrm{w}$ ). After that, the sample was put in the incubator shaker at $30^{\circ} \mathrm{C}$ for $24 \mathrm{~h}$.

\subsubsection{Preparation of 5-FU.Exo@BC}

First, $22 \mu \mathrm{l} 5$-FU $(50 \mathrm{mg} / \mathrm{ml})$ and $0.55 \mathrm{mg}$ Exo were mixed under continues stirring $(100 \mathrm{rpm})$ for $1 \mathrm{~h}$ at room temperature and then, $978 \mathrm{ml}$ DI water was added into prepared 5-FU.Exo solution. After that, according to the above sample, a BC sheet was placed into the solution (the ratio of 5-FU to Exo and BC was $2: 1: 4 \mathrm{w} / \mathrm{w}$ ) and incubated in the incubator shaker at $30^{\circ} \mathrm{C}$ for $24 \mathrm{~h}$.

Finally, the BC sheet was removed with forceps from all of the above prepared samples and dried at incubator $37^{\circ} \mathrm{C}$ for characterization. However, three samples of each system were separately transferred to the dialysis bag containing $1 \mathrm{ml}$ PBS for the release experiments. The remaining solution was stored for determination of unloaded drug.

\subsection{Drug loading and release experiment}

\subsubsection{Standard Equation}

The absorption of the various concentrations of $5-\mathrm{FU}(0-0.34 \mathrm{mg} / \mathrm{ml})$ was recorded at characteristic wavelength of 5-FU $(325 \mathrm{~nm})$. Then, the recorded absorption versus concentration was plotted and the best linear equation was determined. The concentration of unknown samples was estimated [20] by the obtained standard equation as $A=m C$, where $A$ was absorption of each sample, $m$ was slope and $C$ was concentration.

\subsection{3. determination of Drug Loading and Entrapping Percentage}

The drug loading (\%DL) and encapsulation efficiency (\%EE) were determined by the following equations [21]: 
$\% \mathrm{DL}=\left(\mathrm{M}_{0} / \mathrm{M}\right) \times 100(1)$

$\% \mathrm{EE}=\left(\mathrm{M}_{0} / \mathrm{M}_{1}\right) \times 100(2)$

Where $M_{0}, M_{1}$, and $M$ were weight of loaded 5-fluorouracil, the total weight of 5-fluorouracil, and weight of carrier, respectively.

The release of AZT from LPN was studied using dialysis bag method. The hybrid nanoparticles containing $5 \mathrm{mg}$ drug were dispersed in $5 \mathrm{~mL}$ PBS solution $(\mathrm{pH} 7.4)$ in preheated dialysis membrane (Spectra/Poresize; 12000 Da cutoffs, CA, USA). This dialysis bag was immersed in a beaker containing PBS $(50 \mathrm{~mL})$ and stirred at $37^{\circ} \mathrm{C}$. The sample $(3 \mathrm{~mL})$ was withdrawn from the beaker at predetermined intervals to estimate released AZT. An equal volume of fresh buffer was introduced to the beaker containing the dialysis bag. The AZT release was estimated specrophotometrically at $265 \mathrm{~nm}$.

\subsubsection{Drug Release experiment}

The study of 5-FU release from designed carriers was performed by the dialysis bag method. So that, the three systems of 5-FU, 5-FU@BC and 5-FU.Exo@BC (1 ml) was separately embedded into a dialysis bag (12 kDa cutoffs) and immersed in a release medium containing $6 \mathrm{ml}$ of PBS solution. Then, each system put in shaker at $37^{\circ} \mathrm{C}$ and $500 \mu \mathrm{l}$ sample was withdrawn from it at the certain time intervals and an equal volume of fresh buffer was introduced to the beaker. This experiment was performed two times. After that, the amount of drug release was analyzed with absorption spectroscopy at $325 \mathrm{~nm}$ and the cumulative drug release percentage was determined by the following equation [21]:

\%cumulative release $=M_{t} / M_{0} \cdot 100$ (3)

The release rate ( $r)$ was also determined using Eq. $5[22,23]$ :

$r=M_{t} / t(4)$

where, $M_{t}$ was weight of released drug in time $(t)$ and $M_{0}$ was initial weight.

\subsubsection{Release Mechanism}

The release mechanism was evaluated using the following three mathematical models [24]:

- Zero-order model

$M_{t}=M_{0}+k_{0} t(5)$

where $M_{t}$ is the amount of released drug in time $t, M_{0}$ is the starting amount of the drug in the solution (in most cases, $\mathrm{M}_{0}=0$ ) and $\mathrm{k}_{0}$ is the zero-order release constant. The zero-order kinetic model and the drug concentration are independent.

- First-order model 
$\log M_{t} / M_{0}=-k_{1} t / 2.303(6)$

where $M_{t}, M_{0}$, and $t$ are as in the Zero-order model, and $k_{1}$ is the first-order release constant. The first-order kinetic model is independent of drug concentration.

- Korsmeyer-Peppas model

$\log M_{t} / M=\log k_{p}+\operatorname{nlogt}(7)$

where $M_{t} / M$ is the fraction of drug release at time $t, n$ is the release index and the value to predict the mechanism of release $(n<0.43$ was Fickian diffusion and $n$ between $0.43-1$ was non-Fickian diffusion in the drug release process) and $\mathrm{k}_{\mathrm{p}}$ is the Korsmeyer-Peppas release rate constant.

furthermore, the release kinetic parameters were determined as follow [22, 23]:

$t / C_{t}=a+\beta t(8)$

$C_{t}$ is the amount of drug released at time $t, \beta=1 / C_{\max }$ is the inverse of the maximum amount of drug released, $a=1 /\left(C_{\max }\right)^{2} k_{\text {rel, }}, k_{\text {rel }}$ is the kinetic constant of release and equals the inverse of the initial release rate $\left(r_{0}\right)$ [22].

\subsection{Cytotoxicity measurement}

The MTT assay is a colorimetric assay for measuring cell metabolic activity. It is based on the ability of nicotinamide adenine dinucleotide phosphate (NADPH)-dependent cellular oxidoreductase enzymes to reduce the tetrazolium dye MTT to its insoluble formazan, which has a purple color. This assay, therefore, measures cell viability in terms of reductive activity as the enzymatic conversion of the tetrazolium compound to water-insoluble formazan crystals by dehydrogenases occurring in the mitochondria of living cells although reducing agents and enzymes located in other organelles, such as the endoplasmic reticulum are also involved [25]. Therefore, the cell viability of 5-FU, 5FU@BC and 5FU.Exo@BC onto HT29 cancer cell line can be evaluated by MTT assay. For this reason, the harvested HT-29 cells that grown in the complete medium (RPMI supplemented with streptomycin and penicillin $(5 \mathrm{lg} / \mathrm{mL})$, heat-inactivated fetal calf serum (10\%) and $2 \mathrm{mM}$ glutamine) at $37^{\circ} \mathrm{C}$ in an incubator containing $5 \% \mathrm{CO}_{2}$ and $95 \%$ air atmosphere, were seeded into 24 -well plates with the concentration of $5 \times 10^{4}$ cells/well. Afterwards, to each one of the cultured media well containing the cancer cells were separately added 5-FU, 5FU@BC and 5FU.Exo@BC and then, incubated for 48 h. After 48 h of incubation, the cells were treated with $50 \mu \mathrm{l}$ of MTT (5 mg/ml PBS) and incubated for $4 \mathrm{~h}$ at $37^{\circ} \mathrm{C}$. When the incubation finished, $150 \mu \mathrm{l}$ of DMSO was mixed to dissolve the colored crystals of produced formazan.

Finally, the absorbance was recorded at $630 \mathrm{~nm}$ using ELISA reader. The results reported as cell viability percentage at least three independent experiments and calculated as follow [26]:

$\%$ cell viability $=\left(A_{\text {treated }} / A_{\text {control }}\right) \times 100$ (9) 
where $A_{\text {treated }}$ and $A_{\text {control }}$ were absorbance of the treated cells and untreated cells, respectively.

\section{Results And Discussion \\ 3.1. Characterization}

The FTIR spectra of BC, 5-FU, 5-FU.Exo, 5-FU@BC and 5-FU.Exo@BC were recorded (Fig. 1a) and mentioned the peak position was changed after the conjugation. So that, the main features of 5-FU spectra were stretching and bending vibrations of $-\mathrm{NH}$ group around $3658 \mathrm{~cm}^{-1}$ and $1649 \mathrm{~cm}^{-1}$, respectively [27]. The strong bands at $1402 \mathrm{~cm}^{-1}$ and $1684 \mathrm{~cm}^{-1}$ were attributed to $C-F$ and $C=0$ amide. The main vibrational bands of $\mathrm{BC}$ were appeared at $1076 \mathrm{~cm}^{-1}$ (strong band; $\mathrm{C}-\mathrm{O}$ group) and around $3338 \mathrm{~cm}^{-1}$ (broad band; -OH group). The shift of vibration bands of $5-\mathrm{FU}$ and $\mathrm{BC}$ when the loading between them was performed, indicated that the 5-FU@BC was formed. Besides the changes of C-F vibrational band $\left(1428 \mathrm{~cm}^{-1}\right),-\mathrm{NH}$ bands of 5 -FU and $\mathrm{C}-\mathrm{O}$ band of $\mathrm{BC}$ were almost disappeared that confirmed the conjugation between $-\mathrm{NH}$ and $-\mathrm{CO}$ groups. Furthermore, the FU.Exo spectrum showed the removal of $-\mathrm{NH}$ group of 5-FU that maybe due to the binding between 5-FU with amide groups of Exo [28]. In addition, the band shift was mentioned to $1718 \mathrm{~cm}^{-1}, 1651 \mathrm{~cm}^{-1}$ and $1419 \mathrm{~cm}^{-1}$ for $\mathrm{C}=\mathrm{O}_{\text {amide }}$ $\mathrm{NH}_{\text {bending }}$ and C-F, respectively. The comparison of 5-FU.Exo@BC spectrum with the other spectra was also shown the main vibrational band changes that attributed to the binding formation of 5-FU.Exo and BC. Also, the broad bands of $\mathrm{O}-\mathrm{H}$ stretching vibrations and $\mathrm{C}-\mathrm{H}$ of methyl and methylene groups appeared in the spectral region $3600-3000 \mathrm{~cm}^{-1}$ and $1000-650 \mathrm{~cm}^{-1}$, respectively, for all of the spectra.

The DSC analysis of BC, 5-FU@BC and 5-FU.Exo@BC was performed and recorded as shown in Fig. 1b, the degradation peak of $\mathrm{BC}$ is visible at around $343^{\circ} \mathrm{C}$ and the peak at the low temperature is due to the removal of the surface water from the sample. The characteristic sharp peak of the parent 5-FU@BC sample was shown at around $320-350^{\circ} \mathrm{C}$. Thermal transformation occurred at $320-370^{\circ} \mathrm{C}$, where changing the thermal behavior could be due to a change in the physical form of 5 -FU in BC. Further, the degradation peak of BC showed up in 5-FU@BC. Also, a crucial result in the 5-FU.Exo@BC was that peaks were no longer visible since degradation did not accompany the release of the drug, so the loaded drug released on the carrier. This key factor along with the positive effect of exosomes on the designed carrier demonstrated favorable thermal stability. Finally, the thermal analysis study indicates that the 5FU.Exo@BC designed here consisted mostly of 5-FU.

The analysis of XRD (Fig. 4c), showed that the characteristic peaks of pure BC were located at approximately $42^{\circ}$ owing to the linear structure of semi crystalline homopolysaccharide. The XRD pattern of 5-FU.Exo@BC was similar to that of pure BC, since the exosome as an amorphous material did not exhibit characteristic peaks. However, according to data shown in 5-FU.Exo@BC, it appears that the addition of 5-FU.Exo@BC was shifting the diffraction angle from $22.79^{\circ}$ to $23.18^{\circ}$, which was due to the increased hydrogen bonds formed between hydrogens of amide group and oxygen of the carbonyl group, forming the body of the protein. In addition, the hydrogen-bonding network within the a-helix served to 
stabilize the conformation and interaction between the drug and exosome with BC. Also, the crystallinity of part of $\mathrm{BC}$ resulted in having sharper peaks in the range of $20^{\circ}-24^{\circ}$. Pure 5 -FU has a crystalline structure, with a sharp diffraction peak at around $2 \theta=28.71^{\circ}$ [29], whereas the results here noticeably indicated that 5-FU@BC did not have any sharp peak related to 5-FU, because the drug was possibly entrapped within the composites of the carrier. Further, the crystalline structure of the pure drug may become non-crystalline after it is encapsulated within the carrier.

The SEM images of BC, 5-FU.Exo, 5-FU@BC and 5-FU.Exo@BC were shown in Fig. 4d. the surface of BC shows the regular and uniform fibers with an average diameter of $42.0 \mathrm{~nm} \pm 19.2 \mathrm{~nm}$ and 5-FU.Exo illustrated the cylindrical structure with a width of $260 \pm 92.2 \mathrm{~nm}$. However, the agglomeration between nanoparticles of 5-FU.Exo was clearly demonstrated. After the conjugation of 5-FU.Exo to BC (Fig. 4d-IV), the presence of 5-FU.Exo was confirmed as the dispersed bar into BC network structure $(57.5 \pm 9.6 \mathrm{~nm})$ as shown with yellow arrows with $82.0 \pm 13.0 \mathrm{~nm}$. In addition, Exos were caused the more dispersity in 5FU.Exo@BC in comparison to 5-FU@BC (width size of 5-FU and BC was $80.0 \pm 14.1 \mathrm{~nm}$ and $37.5 \pm 15 \mathrm{~nm}$, respectively, comparison of III and IV of Fig. 4 d).

\subsection{Drug Loading and Release Studies 3.2.1. Standard plot}

For calculation of unknown concentrations of 5-FU, first, the standard plot was drawn as absorbance versus the various concentrations of $5-\mathrm{FU}$ in the range of $0-1.375 \mathrm{mg} / \mathrm{ml}$ (Fig. 2). Second, the standard equation was obtained by the best straight-line equation that was $A=0.2218[5-F U], R^{2}=0.99$.

\subsubsection{Determination of \%DL and \%EE}

The \%DL and \%EE were calculated using Eqs. 2 and 3. The results showed that \%DL values were $33.56 \pm 1.18 \%$ and $34.34 \pm 0.58 \%$ for 5-FU@BC and 5-FU.Exo@BC, respectively. Noticeably, \%EE values of 5-

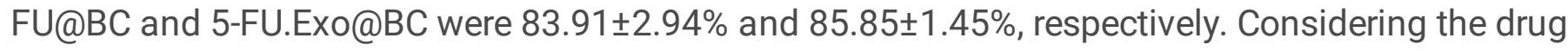
loading percentage of most nanocarriers is generally less than $10 \%$ [30], the above designed carriers were improved the drug loading that was due to conjugating the drug to $\mathrm{BC}$ as a polymer with various binding sites. The drug loading percentage of calcium alginate/sodium cellulose sulfate microcapsule for BSA was 38.14\% [31], Ketamin@PEG-PLGA was 39.1\% [32] and also, paclitaxel@BSA nanoparticles was 27.1\% [30] that comparable with the achievement results of this study. Additionally, encapsulation efficiency values were upper than folic acid-loaded in a chitosan nanoparticles and cellulose nanocrystals (62\%) [33] and zidovudine-loaded in a carboxy methyl cellulose and compritol-PEG carrier (18\%) [34] and in the range of paclitaxel loaded poly(N-vinylpyrrolidone)-b-poly(epsilon-caprolactone) nanoparticles [30].

Therefore, the two nanocarrirs containing 5-FU had acceptable loading behavior. However, the presence of EXO had no significant effects on the two parameters.

\subsubsection{Release behavior}


Cumulative release profiles of 5-FU, 5-FU@BC, and 5-FU.Exo@BC were presented in Fig. 3. The drug release was explosively complete at 5-FU and 5-FU@BC system during $29 \mathrm{~h}$ and $53 \mathrm{~h}$, respectively. In respect of the curves, the presence of $\mathrm{BC}$ was caused a rather slow release compared to 5 -FU alone. Furthermore, 5-FU.Exo@BC showed a significant sustained release during $168 \mathrm{~h}$ compared to the above mentioned systems, owing to the release of 5-FU from Exo and BC. As shown in Fig. 3b, the release rate of the novel 5-FU.Exo@BC indicated also a slow, constant, and controlled within a specific period of time (20-168 h) that confirmed the sustained release of the novel designed system of 5-FU load into Exo and $\mathrm{BC}$ while release rate of only 5-FU was greater than the other systems of 5-FU@BC, and 5-FU.Exo@BC. In addition, the release rate behavior of 5-FU released from BC was similar to 5-FU.Exo@BC with the higher rate of release. Therefore, the presence of Exo with $\mathrm{BC}$ led to a more extended period of 5-FU release and the slower release rate. This despite the fact that tamoxifen citrate released from ethyl cellulose during 36 $\mathrm{h}$ [35] and $10 \%$ of Doxorubicin was release from Cellulose nanocrystals within 100 [36].

\subsubsection{Kinetic behavior}

Zero-order, First-order, and Korsmeyer-Peppas mathematical models were employed for the determination of mechanism mode. The correlation coefficients of three kinetic models are shown in Table 1. Based on the results, the release profile of 5-FU, 5-FU@BC and 5-FU.Exo@BC was fitted well with Korsmeyer-Peppas release kinetic model and the $\mathrm{n}$ value of $5-\mathrm{FU}$ was greater than 0.85 , hence, the release behavior followed by Fickian diffusion and 5-FU@BC and 5-FU.Exo@BC were between 0.43-0.85, thus, the drug release followed by non-Fickian diffusion [31]. Therefore, BC could affect the drug release behavior.

Furthermore, the results of other kinetic parameters (Table 1 ) revealed that, $C_{\max }$ value was approximately equal to the initial weight of drug, therefore, it was also confirmed the completion of the release. $r_{0}$ values as well as $\mathrm{k}_{\text {rel }}$ values of the three system demonstrated the distinct behavior in 5-FU.Exo@BC that confirms the presence of Exo and the improvement of drug release behavior due to an appropriate designed carrier containing $\mathrm{BC}$ and Exo.

Table 1

The kinetic parameters of various mathematical models

\begin{tabular}{|llllllllll|}
\hline Samples & $\begin{array}{l}\text { Zero- } \\
\text { order }\end{array}$ & $\begin{array}{l}\text { First- } \\
\text { order }\end{array}$ & \multicolumn{2}{l}{ Korsmeyer-Peppas } & \multicolumn{2}{l|}{ Kinetic-Parameters } & \\
\cline { 2 - 12 } & $\mathbf{R}^{2}$ & $\mathbf{R}^{2}$ & $\mathbf{k}_{\mathbf{p}}$ & $\mathbf{n}$ & $\mathbf{R}^{2}$ & $\begin{array}{l}\mathbf{C}_{\text {max }} \\
(\mathbf{m g})\end{array}$ & $\begin{array}{l}\mathbf{k}_{\text {rel }} \\
(\mathbf{h} / \mathbf{m g})\end{array}$ & $\begin{array}{l}\mathbf{r}_{0} \\
(\mathbf{m g} / \mathbf{h})\end{array}$ & $\mathbf{R}^{2}$ \\
\hline 5-FU & 0.72 & 0.31 & 0.39 & 1.05 & 0.99 & 1.33 & 0.15 & 6.63 & 0.93 \\
\hline 5-FU@BC & 0.63 & 0.29 & 0.41 & 0.59 & 0.92 & 0.86 & 0.22 & 4.44 & 0.81 \\
\hline $\begin{array}{l}\text { 5- } \\
\text { FU.Exo@BC }\end{array}$ & 0.79 & 0.55 & 0.28 & 0.60 & 0.97 & 1.26 & 0.01 & 72.38 & 0.95 \\
\hline
\end{tabular}


Continuing studies of the three systems for biomedical application, the viability of HT-29 cancer cell lines towards BC, 5-FU@BC, and 5-FU.Exo@BC was separately performed based on MTT assay. As shown in Fig. 4, the BC sheet had no toxicity and the cell viability percentage of 5-FU.Exo@BC (50.16 \pm 0.51$)$ was lower than 5-FU@BC (69.32 \pm 5.94$)$, whereas, according to release plots (Fig. 3a), after 48 h, 54\% and 98\% of 5-FU were released from BC and Exo@ BC. Hence, the encapsulation of 5-FU into Exo and BC may have prevented the destruction of the drug during release. Therefore, the lower concentration was needed to cell death that was a remarkable achievement to cancer treatment.

\section{Conclusion}

In this study, two drug delivery systems of 5-FU@BC and 5-FU.Exo@BC were successfully prepared and characterized by FTIR, DSC, XRD, and FESEM. The results confirmed the loading of 5-FU into the carriers. Also, the drug loading and encapsulation efficacy percentage were determined and the release behavior of 5-FU@BC and 5-FU.Exo@BC was studied and mentioned the significant sustained release of 5-FU in presence of Exo and $\mathrm{BC}$, whereas, the release of drug from $\mathrm{BC}$ carrier was lower than only 5-FU.

Furthermore, the release mechanism followed by Korsmeyer-peppas model with non-Fickian diffusion for 5-FU@BC and 5-FU.Exo@BC systems. Finally, the cytotoxicity of BC, 5-FU@BC and 5-FU.Exo@BC on the human colon cancer cell line, HT-29, was shown the high cytotoxicity in low concentration of 5-

FU.Exo@BC. Overall, the designed nanocarriers based on cellulose can be introduced as a promising carrier for sustained released of anticancer drugs, especially in presence of exosome as a vehicle for chemotherapy agents that improve drug delivery efficacy and reduce drug side effects.

\section{References}

1. Ho BN, Pfeffer CM, T.K.S.-A. Research A (2017) undefined Update on nanotechnology-based drug delivery systems in cancer treatment, Ar.liarjournals.Org. (n.d.). https://doi.org/10.21873/anticanres.12044

2. Dang JM, Leong KW (2006) Natural polymers for gene delivery and tissue engineering. Adv Drug Deliv Rev 58:487-499. https://doi.org/10.1016/J.ADDR.2006.03.001

3. Patenaude M, Hoare T (2012) Injectable, mixed natural-synthetic polymer hydrogels with modular properties. Biomacromolecules 13:369-378. https://doi.org/10.1021/BM2013982

4. Schorey JS, H.-T.J. of Clinical CV (2016) undefined Extracellular vesicles and infectious diseases: new complexity to an old story, Am Soc Clin Investig. (n.d.). https://www.jci.org/articles/view/81132

5. Jiang XC J.Q.G.-I. journal of Pharmaceutics, undefined 2017, Exosomes as novel bio-carriers for gene and drug delivery,Elsevier. (n.d.). https://www.sciencedirect.com/science/article/pii/S037851731730128X

6. Li L, Gu W, Chen J, Chen W, - Biomaterials ZPX (2014) undefined Co-delivery of siRNAs and anticancer drugs using layered double hydroxide nanoparticles, Elsevier. (n.d.). https://www.sciencedirect.com/science/article/pii/S0142961213015913 
7. T.A.B.-C. drug discovery Technologies, undefined 2015, Targeted cancer therapy: the next generation of cancer treatment, Ingentaconnect.Com. (n.d.). https://www.ingentaconnect.com/content/ben/cddt/2015/00000012/00000001/art00003

8. Longley DB, Harkin DP (2003) J.-N. reviews Cancer, undefined 2003, 5-fluorouracil: mechanisms of action and clinical strategies. Nature Com. https://doi.org/10.1038/nrc1074

9. Wu P, Zhou Q, Zhu H, Zhuang Y, Bao J (2020) Enhanced antitumor efficacy in colon cancer using EGF functionalized PLGA nanoparticles loaded with 5-Fluorouracil and perfluorocarbon. BMC Cancer 20. https://doi.org/10.1186/S12885-020-06803-7

10. Islam SU, UI-Islam M, Ahsan H, Ahmed MB, Shehzad A, Fatima A, Sonn JK, Lee YS (2021) Potential applications of bacterial cellulose and its composites for cancer treatment. Int J Biol Macromol 168:301-309. https://doi.org/https://doi.org/10.1016/j.jbiomac.2020.12.042

11. Gregory DA, Tripathi L, Fricker ATR, Asare E, Orlando I, Raghavendran V, Roy I (2021) Bacterial cellulose: A smart biomaterial with diverse applications. Mater Sci Eng R Reports 145:100623. https://doi.org/https://doi.org/10.1016/j.mser.2021.100623

12. Ul-Islam M, Khan T, Park JK (2012) Water holding and release properties of bacterial cellulose obtained by in situ and ex situ modification. Carbohydr Polym 88:596-603. https://doi.org/https://doi.org/10.1016/j.carbpol.2012.01.006

13. Rühs PA, Storz F, López Gómez YA, Haug M, Fischer P (2018) 3D bacterial cellulose biofilms formed by foam templating. Npj Biofilms Microbiomes 4:21. https://doi.org/10.1038/s41522-018-0064-3

14. Rijal G, Li W (2016) 3D scaffolds in breast cancer research. Biomaterials 81:135-156. https://doi.org/https://doi.org/10.1016/j.biomaterials.2015.12.016

15. Pati F, Jang J, Ha D-H, Won Kim S, Rhie J-W, Shim J-H, Kim D-H, Cho D-W (2014) Printing threedimensional tissue analogues with decellularized extracellular matrix bioink. Nat Commun 5:3935. https://doi.org/10.1038/ncomms4935

16. Jang SC, Kim OY, Yoon CM, Choi DS, Roh TY, Park J, Nilsson J, Lötvall J, Kim YK, Gho YS (2013) Bioinspired exosome-mimetic nanovesicles for targeted delivery of chemotherapeutics to malignant tumors. ACS Nano 7:7698-7710. https://doi.org/10.1021/NN402232G

17. Sheller-miller S, Menon R (2020) Isolation and characterization of human amniotic fluid-derived exosomes, 1st edn. Elsevier Inc.. https://doi.org/10.1016/bs.mie.2020.07.006

18. Mustafa AS, Babaeipour V, Roohi M, Khanchezar S, Archive of SID 11 th International Seminar on Polymer Science and Technology (2014) Enhancement of bacterial cellulose (BC) production by Optimizing of inoculation condition: RSM Approach Archive of SID 11 th International Seminar. on Polymer Science and Techn

19. Khodamoradi N, Babaeipour V, Sirousazar M (2019) Bacterial cellulose/montmorillonite bionanocomposites prepared by immersion and in-situ methods: structural, mechanical, thermal, swelling and dehydration properties. Cellulose 26:7847-7861. https://doi.org/10.1007/s10570-01902666-9 
20. Yu DG, Li XY, Wang X, Chian W, Liao YZ, Li Y (2013) Zero-order drug release cellulose acetate nanofibers prepared using coaxial electrospinning. Cellulose 20:379-389.

https://doi.org/10.1007/s10570-012-9824-z

21. Tang L, Lin F, Li T, Cai Z, Hong B, Huang B (2018) Design and synthesis of functionalized cellulose nanocrystals-based drug conjugates for colon-targeted drug delivery. Cellulose 25:4525-4536. https://doi.org/10.1007/s10570-018-1904-2

22. Fattahian Kalhor N, Saeidifar M, Ramshini H, Saboury AA (2020) Interaction, cytotoxicity and sustained release assessment of a novel anti-tumor agent using bovine serum albumin nanocarrier. J Biomol Struct Dyn 38:2546-2558. https://doi.org/10.1080/07391102.2019.1638303

23. Ziaaddini V, Saeidifar M, Eslami-Moghadam M, Saberi M, Mozafari M (2020) Improvement of efficacy and decrement cytotoxicity of oxaliplatin anticancer drug using bovine serum albumin nanoparticles: Synthesis, characterisation and release behaviour. IET Nanobiotechnol 14. https://doi.org/10.1049/iet-nbt.2019.0086

24. Seera SDK, Kundu D, Banerjee T (2020) Physical and chemical crosslinked microcrystalline cellulosepolyvinyl alcohol hydrogel: freeze-thaw mediated synthesis, characterization and in vitro delivery of 5-fluorouracil. Cellulose 27:6521-6535. https://doi.org/10.1007/s10570-020-03249-9

25. Lü L, Zhang L, Wai MSM, Yew DTW, Xu J (2012) Exocytosis of MTT formazan could exacerbate cell injury. Toxicol Vitr 26:636-644. https://doi.org/10.1016/J.TIV.2012.02.006

26. Xu L, He XY, Liu BY, Xu C, Ai SL, Zhuo RX, Cheng SX (2018) Aptamer-functionalized albumin-based nanoparticles for targeted drug delivery. Colloids Surfaces B Biointerfaces 171:24-30. https://doi.org/10.1016/J.COLSURFB.2018.07.008

27. Javanbakht S, Hemmati A, Namazi H, Heydari A (2020) Carboxymethylcellulose-coated 5fluorouracil@MOF-5 nano-hybrid as a bio-nanocomposite carrier for the anticancer oral delivery. Int J Biol Macromol 155:876-882. https://doi.org/10.1016/J.IJBIOMAC.2019.12.007

28. Mihály J, Deák R, Szigyártó IC, Bóta A, Beke-Somfai T, Varga Z (2017) Characterization of extracellular vesicles by IR spectroscopy: Fast and simple classification based on amide and $\mathrm{C}[\mathrm{sbnd}] \mathrm{H}$ stretching vibrations, Biochim. Biophys. Acta - Biomembr 1859:459-466. https://doi.org/10.1016/j.bbamem.2016.12.005

29. Zhu W, Wan L, Zhang C, Gao Y, Zheng X, Jiang T, Wang S (2014) Exploitation of 3D face-centered cubic mesoporous silica as a carrier for a poorly water soluble drug: Influence of pore size on release rate. Mater Sci Eng C 34:78-85. https://doi.org/10.1016/J.MSEC.2013.08.014

30. Liu Y, Yang G, Jin S, Xu L, Zhao CX (2020) Development of High-Drug-Loading Nanoparticles. Chempluschem 85:2143-2157. https://doi.org/10.1002/cplu.202000496

31. Wu QX, Wang DD, Su T, Du Cheng X, Xu X, Chen Y (2017) Self-assembly of polyelectrolyte complexes microcapsules with natural polysaccharides for sustained drug release. Cellulose 24:4949-4962. https://doi.org/10.1007/s10570-017-1454-z

32. Han FY, Liu Y, Kumar V, Xu W, Yang G, Zhao CX, Woodruff TM, Whittaker AK, Smith MT (2020) Sustained-release ketamine-loaded nanoparticles fabricated by sequential nanoprecipitation. Int $J$ 
Pharm 581:119291. https://doi.org/10.1016/j.ijpharm.2020.119291

33. Okamoto-Schalch NO, Pinho SGB, de Barros-Alexandrino TT, Dacanal GC, Assis OBG, Martelli-Tosi M (2020) Production and characterization of chitosan-TPP/cellulose nanocrystal system for encapsulation: a case study using folic acid as active compound. Cellulose 27:5855-5869. https://doi.org/10.1007/s10570-020-03173-y

34. Joshy KS, Snigdha S, George A, Kalarikkal N, Pothen LA, Thomas S (2017) Core-shell nanoparticles of carboxy methyl cellulose and compritol-PEG for antiretroviral drug delivery. Cellulose 24:47594771. https://doi.org/10.1007/s10570-017-1446-z

35. Li XY, Bin Zheng Z, Yu DG, Liu XK, Qu YL, Li HL (2017) Electrosprayed sperical ethylcellulose nanoparticles for an improved sustained-release profile of anticancer drug. Cellulose 24:5551-5564. https://doi.org/10.1007/s10570-017-1498-0

36. Tortorella S, Maturi M, Dapporto F, Spanu C, Sambri L, Comes Franchini M, Chiariello M, Locatelli E (2020) Surface modification of nanocellulose through carbamate link for a selective release of chemotherapeutics. Cellulose 27:8503-8511. https://doi.org/10.1007/s10570-020-03390-5

\section{Figures}



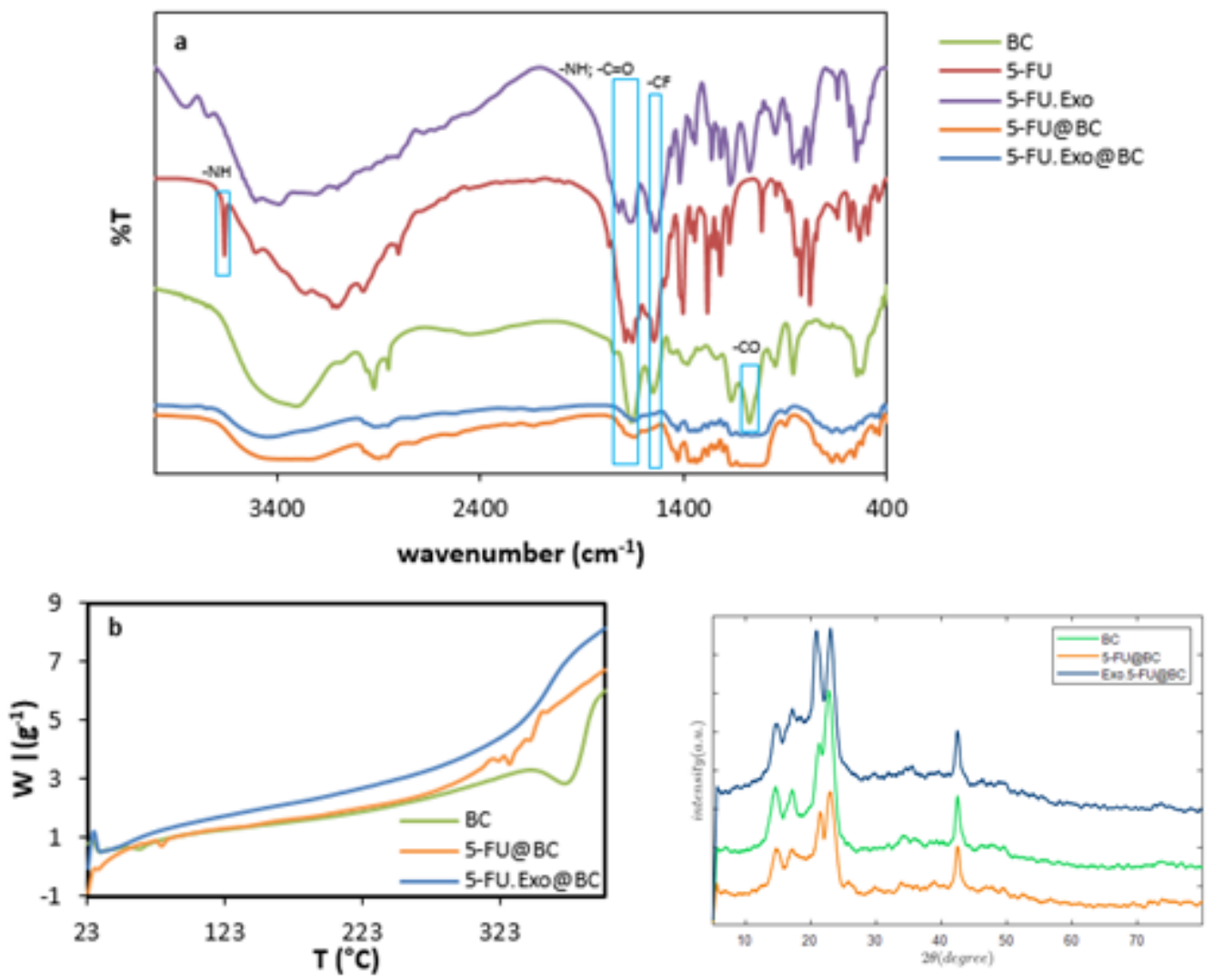

d
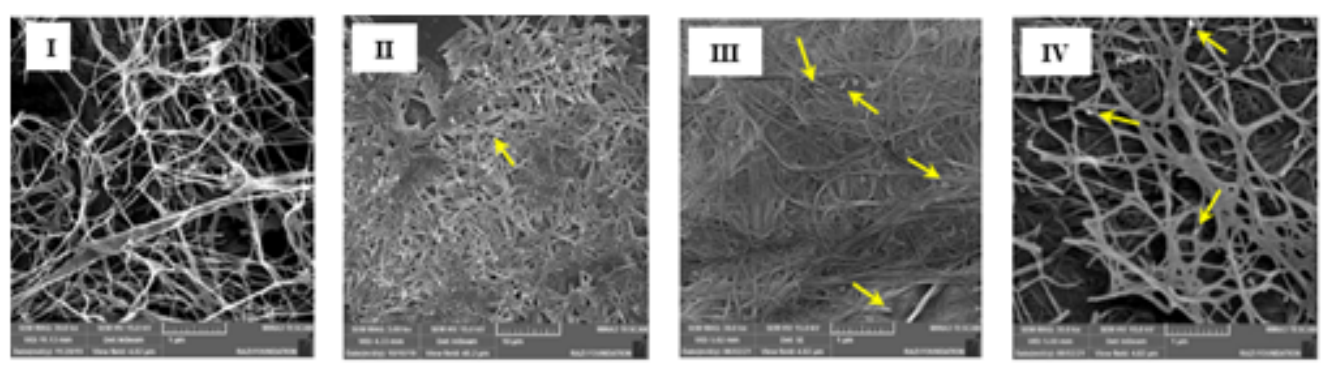

\section{Figure 1}

FTIR analysis of BC (green line), 5-FU (red line), 5-FU.Exo (purple line), 5-FU@BC (orange line) and 5FU.Exo@BC (blue line). DSC analysis of BC (green line), 5-FU@BC (orange line) and 5FU.Exo@BC (blue line).XRD analysis of BC (green line), 5-FU@BC (yellow line), and 5-FU.Exo@BC (blue line). FESEM images of I) BC, II) 5-FU.Exo, III) 5-FU@BC and IV) 5-FU.Exo@BC. 


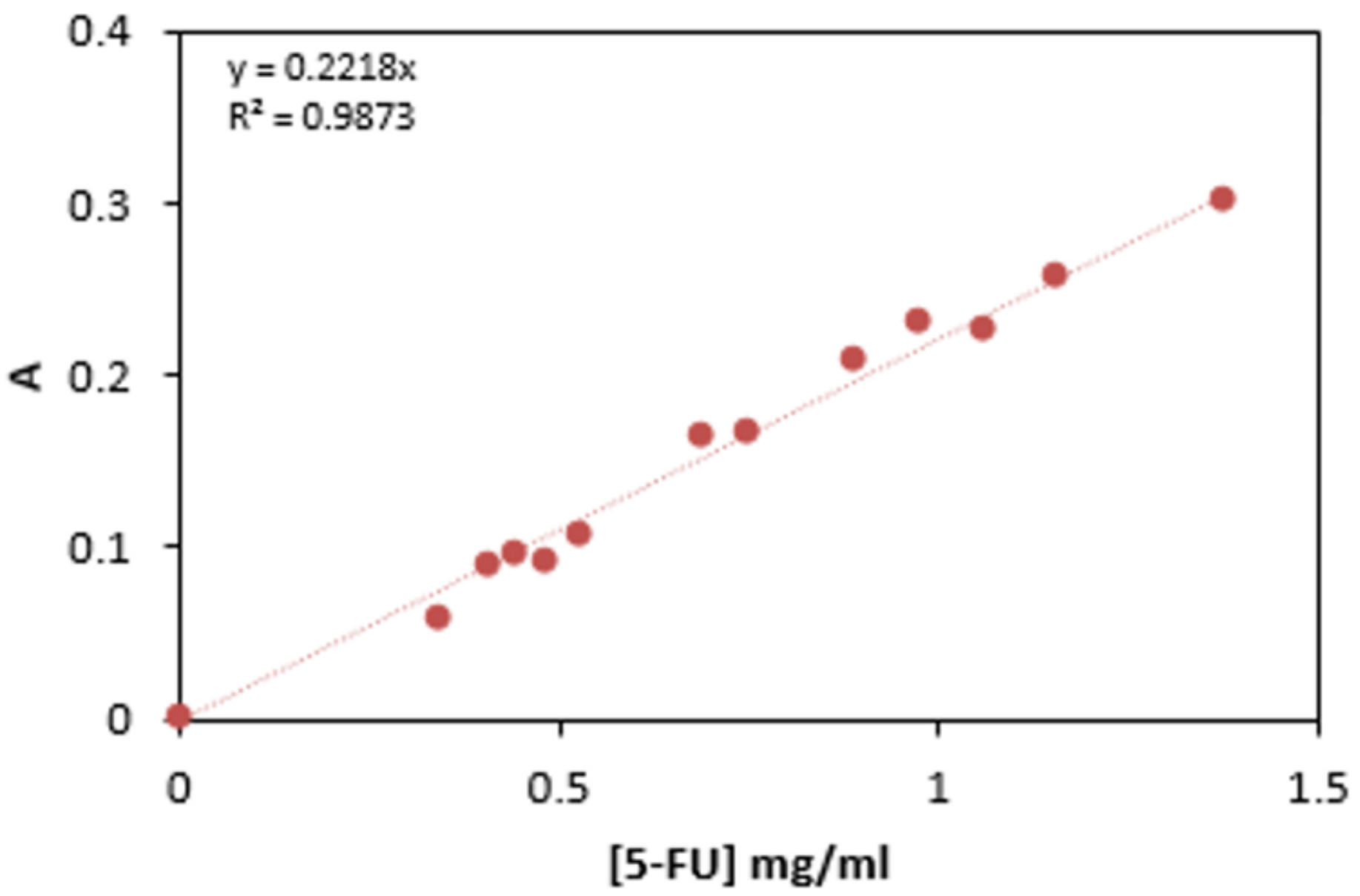

Figure 2

The standard plot of $5-\mathrm{FU}(0-1.375 \mathrm{mg} / \mathrm{ml})$ 

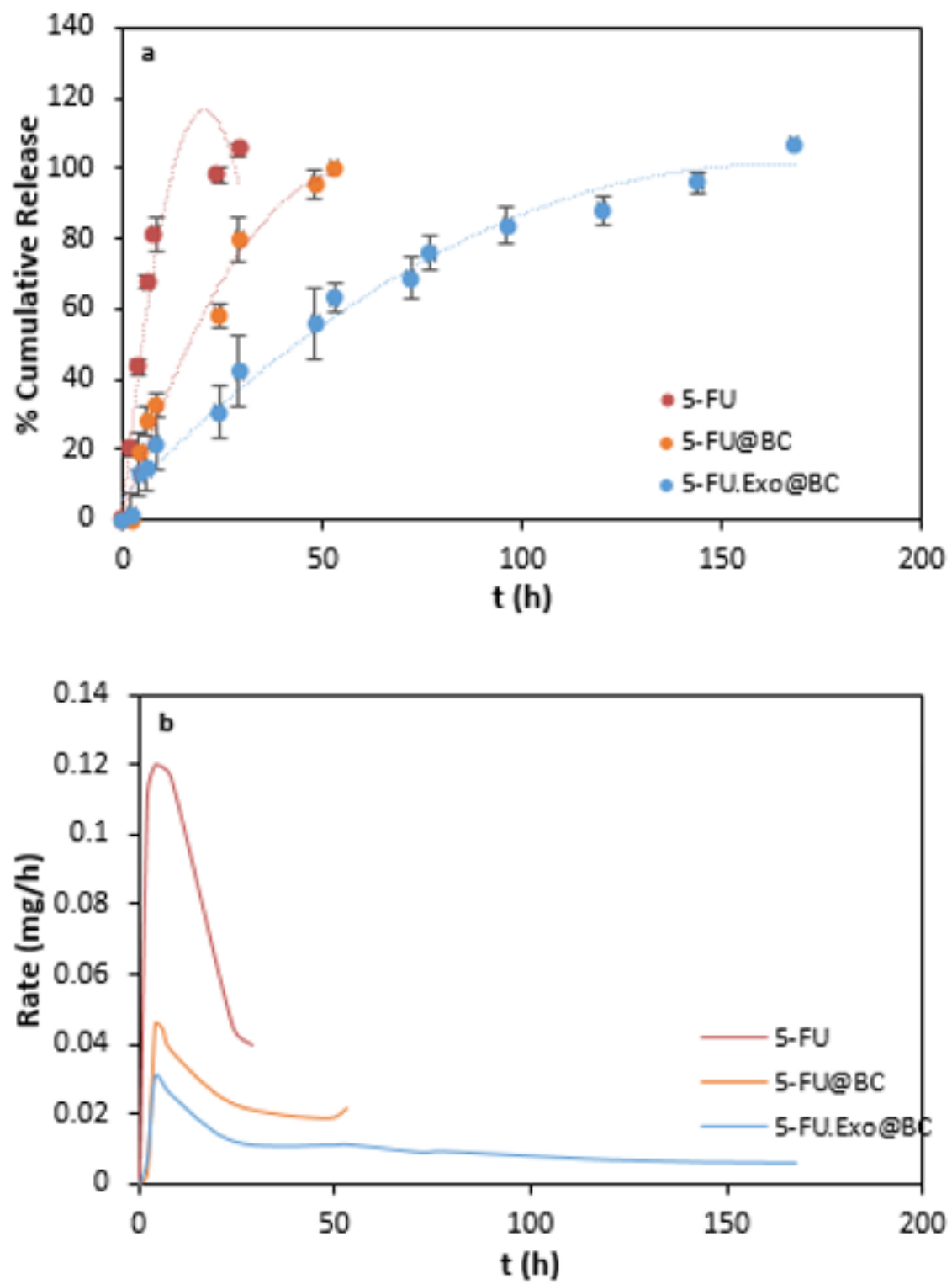

Figure 3

Cumulative release curve and the diagram of the rate of drug release of A) 5-FU (red line), B) 5-FU@BC (orange line), and C) 5-FU.Exo@BC (blue line) systems 


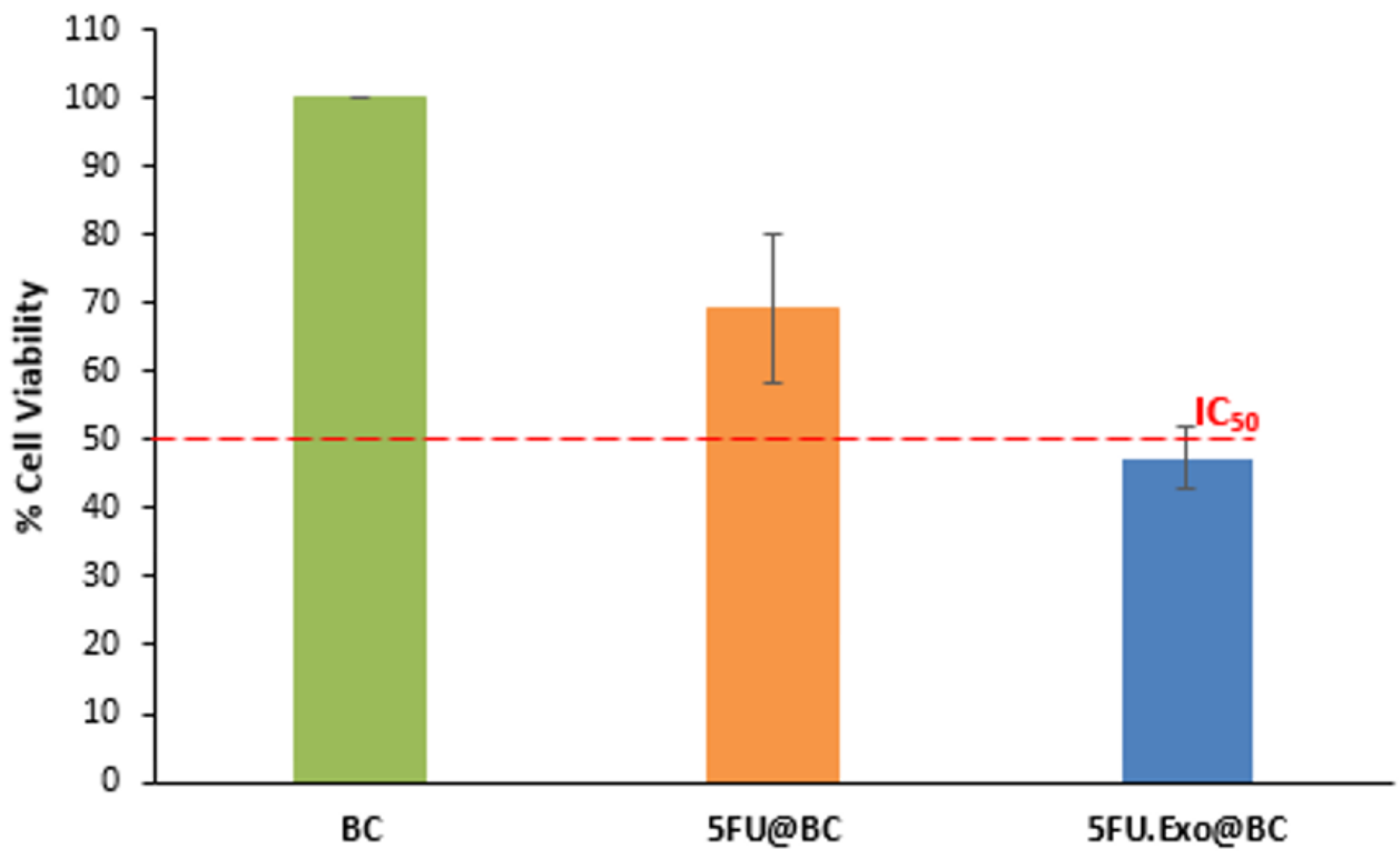

Figure 4

The cell viability of control (BC), 5-FU@BC, and 5-FU.Exo@BC in HT-29

\section{Supplementary Files}

This is a list of supplementary files associated with this preprint. Click to download.

- SUPP.docx 